\title{
FOLKSONG DALAM TRADISI MA'AROLO LANI MALA'APA DI PELAUW MALUKU TENGAH (KAJIAN MAKNA)
}

\author{
Susi Hardila Latuconsina \\ Universitas Pattimura Ambon \\ Rusli.hiasikal@gmail.com
}

\begin{abstract}
ABSTRAK
Nyanyian rakyat dalam perkawinan adat Pelauw adalah produk budaya masyarakat Pelauw. Sebagai produk budaya, nyanyian rakyat dalam ritual perkawinan adat Pelauw digunakan sebagai media ekspresi seni untuk menyampaikan berbagai hal tentang kehidupan manusia, di samping sebagai media hiburan rakyat. Penelitian ini bertujuan mendeskripsikan makna folksong dalam tradisi Ma'arolo Lani Mala'apa di desa Pelauw Kecamatan Pulau Haruku Maluku Tengah. Jenis penelitian ini adalah deskriptif kualitatif dengan pendekatan ancangan hermeneutika untuk mengkaji makna nyanyian rakyat dalam ritual perkawinan adat dengan sumber data Folksong dalam tradisi Ma'arolo Lani Mala'apa di desa Pelauw Kecamatan Pulau Haruku Maluku Tengah. Berdasarkan hasil penelitian, disimpulkan makna folksong dalam tradisi Ma'arolo Lani Mala'apa di desa Pelauw Kecamatan Pulau Haruku Maluku Tengah berfungsi sebagai media kritik sosial dalam ritual perkawinan adat Pelauw dan mengandung nilai filosofis, religius dan nilai-nilai sosial.
\end{abstract}

Kata Kunci: Folksong, makna dan desa Pelauw, tradisi Ma'arolo Lani Mala'apa.

ABSTRACT

The folksong in Pelauw custom marriage is a cultural product of Pelauw community. As a product of the culture, the folksong in marriage ritual of Pelauw custom is used as a medium of artistic expression for delivering the things about human life, beside as a medium of folk entertainment. This study aims to describe the meaning of folksong in Ma'arolo Lani Mala'apa tradition at Pelauw village, sub district Haruku island Central Maluku. The type of this study is qualitative descriptive with hermeneutics design approach to review the meaning of folksong in custom marriage rituals with the folksong as source of data in Ma'arolo Lani Mala'apa tradition at Pelauw village, sub district Haruku island Central Maluku. Based on the result of this study, it is concluded the meaning of folksong in in Ma'arolo Lani Mala'apa tradition at Pelauw village, sub district Haruku Island Central Maluku has the function as a medium of social criticism in marriage ritual of Pelauw custom and contain the philosophical values, religious, social values.

Keywords: Folksong, Ma'arolo Lani Mala'apa tradition, Meaning, Pelauw village.

PENDAHULUAN

Ma'arolo Lani merupakan salah satu jenis tradisi yang terdapat dalam proses perkawinan adat (Mala'apa) yang tetap dilestarikan oleh masyarakat Pelauw. Ma'arolo Lani berasal dari bahasa Hatuhaha yang 
berarti bernyanyi atau berpantun. Berpantun dalam tradisi Ma'arolo Lani merupakan sebuah kegiatan hiburan berupa petuah-petuah dan nasehat dengan cara ditembangkan atau dinyanyikan oleh sekelompok orang yang biasa disebut Ma'alani dan diungkapkan dalam bahasa Hatuhaha dan adapula dalam bahasa Melayu Ambon serta diiringi musik tipa (gendang) yang bersemangat.

Tradisi Ma'arolo Lani tumbuh dan berkembang di tengah-tengah masyarakat. Tradisi tersebut akan terancam keberadaannya jika tidak dilestarikan. Kelestarian penyelenggaraan tradisi Ma'arolo Lani adalah hal yang sering dilakukan pada ritual-ritual adat dan keagamaan, seperti tradisi ini yang tampak pada ritual perkawinan adat yang selanjutnya dijadikan fokus penelitian. Sejak dahulu, Desa Pelauw adalah salah satu daerah yang menjadi tempat tumbuh berkembangnya tradisi Ma'arolo Lani. Di Desa Pelauw, biasanya tradisi Ma'arolo Lani diselenggarakan setiap kali ada ritual perkawinan adat (Mala'apa) dan ritual-ritual adat keagamaan yang lainnya. Namun, seiring berkembangnya zaman tradisi Ma'arolo Lani bisa saja ditinggalkan perlahan oleh masyarakat penerusnya.

Tradisi Ma'arolo Lani merupakan bagian dari folklore karena tradisi Ma'arolo Lani disampaikan oleh penembang (Ma'alani) secara lisan. Menurut Danandjaja (1997:1), folk adalah sekelompok orang yang memiliki ciri pengenal fisik, sosial, dan kebudayaan sehingga dapat dibedakan dari kelompok yang lain. Dengan demikian, folk merupakan kolektif yang memiliki tradisi dan diwariskan dari generasi ke generasi berikutnya. Lore berarti sebagai tradisi yang diwariskan secara turuntemurun secara lisan atau melalui contoh yang disertai gerak isyarat atau alat pembantu pengingat. Jadi, maksud dari folklor adalah sebagian kebudayaan kolektif yang tersebar dan diwariskan secara tradisional dalam ragam berbeda-beda, baik bentuk lisan atau contoh disertai alat bantu mengingat.

Tradisi Ma'arolo Lani sangat populer dikalangan masyarakat. Penyanyiannya menjadi hiburan tersendiri bagi pendengarnya. Selain sebagai sarana hiburan juga merupakan sastra klasik yang mengandung ajaran luhur, tuturan lisan yang hebat, aturan yang amat baik, pengetahuan yang indah, dan bahasa yang bernilai tinggi.

Dalam perkembangannya, karya sastra klasik pada zaman modern mulanya diabaikan keberadaannya. Perhatian masyarakat pada saat ini seakan hanya tertuju pada karya sastra baru seperti novel dan cerpen. Bahkan, tidak jarang dikalangan masyarakat zaman sekarang merasa enggan untuk menyaksikan tradisi kuno bernilai sastra yang biasanya diselenggarakan di daerahnya masing-masing. Memahami, mengenal, dan melestarikan budaya dan sastra daerah berarti menghargai hidup sebagai seni. Seni yang dimaksudkan adalah bentuk-bentuk estetik yang timbul pada masyarakat dengan cerminan budaya, pengetahuan, aktivitas, dan sastra yang bervariasi. Salah satu media budaya yang menggambarkan latar belakang sosial suatu daerah adalah melalui bidang sasra lisan. Sastra lisan yang akan dibahas pada penelitian ini adalah nyanyian rakyat sebagai cakupan dari bidang Folklor di daerah Maluku. Hampir sebagian besar nyanyian rakyat daerah Maluku belum diteliti, hanya berupa wacana yang disampaikan pada orang tertentu yang ingin mengetahui nyanyian rakyat tersebut. 
Peneliti dalam penelitian ini memperkenalkan folksong (Lani) dalam tradisi Ma'arolo Lani Mala'apa yang terdapat di Desa Pelauw Kecamatan Pulau Haruku Maluku Tengah. Tradisi ini diteliti dengan cara menyaksikan secara langsung dan biasanya digunakan dalam proses pernikahan adat. Tradisi ini menggunakan bahasa Hatuhaha. Penembang mendendangkannya dengan dialek Pelauw dan dengan ciri khas tersendiri. Hal tersebut memang menjadi ciri khas dan keunikan tersendiri dalam tradisi Ma'arolo Lani yang ada di Desa Pelauw. Fenomena tersebut yang mendasari peneliti untuk memperkenalkan tradisi Ma'arolo Lani yang ada di Desa Pelauw dengan cara mengungkapkan ide-ide pokok, baik yang berkembang dalam bagian besar maupun kecil folksong dalam tradisi Ma'arolo Lani Mala'apa. Tujuannya adalah agar masyarakat sadar akan pentingnya menjaga kearifan budaya lokal.

Berdasarkan pemaparan latar belakang di atas dapat disimpulkan bahwa kesusastraan Hatuhaha dalam hal ini sastra Pelauw juga tidak kalah berharga dibandingkan kesusastraan yang lainnya. Namun, penelitian mengenai kesusastraan yang ada dalam masyarakat Pelauw masih jarang dilakukan. Dengan demikian, peneliti akan menganalisis tentang Folksong dalam Tradisi Ma'arolo Lani Mala'apa di Desa Pelauw Kecamatan Pulau Haruku Maluku Tengah (Kajian Bentuk, Makna, dan Fungsi).

Penelitian ini diharapkan dapat memberikan sumbangan informasi dan dokumentasi bagi masyarakat dan pemerintah setempat mengenai pentingnya menjaga dan memperhatikan kelestarian tradisi lokal agar tradisi-tradisi yang semula berfungsi sebagai alat legitimasi budaya lokal tidak terancam kepunahannya. Di samping itu juga agar dapat menggugah minat peneliti-peneliti lain untuk meneliti tradisi budaya pada masyarakat Pelauw dengan objek dan kajian yang lebih kompleks.

Penelitian ini dilakukan berdasarkan pada sifat-sifat pendekatan kualitatif, seperti yang dinyatakan Bogdan dan Biklen (1982:27-29). Pertama, penelitian ini mengutamakan peran latar alami, karena data diambil dari konteks yang sebenarnya, yakni dari nyanyian-nyanyian dalam tradisi Ma'arolo Lani Mala'apa. Kedua, dalam penelitian ini, peneliti sebagai instrument penelitian karena peneliti berperan pula dalam dalam proses penyanyian. Dengan demikian, peneliti menggunakan teknik pengumpulan data observasi partisipan selain nonpartisipan. Ketiga, penelitian ini menggunakan data yang sifatnya deskriptif, berupa data nyanyian dalam tradisi Ma'arolo Lani Mala'apa. Data-data tersebut berupa folksong. Data-data tersebut dijabarkan dan ditranskripsikan secara lengkap melalui keterangan referensi yang menjelaskan keterangan-keterangan konteks dan makna dari folksong dalam tradisi Ma'arolo Lani Mala'apa.

Jenis penelitian yang digunakan dalam penelitian Folksong dalam Tradisi Ma'arolo Lani Mala'apa di Desa Pelauw Kecamatan Pulau Haruku Maluku Tengah (Kajian Makna) adalah jenis penelitian deskriktif. Penelitian deskriptif digunakan dalam penelitian ini karena akan menjelaskan dan mendeskripsikan secara rinci folksong dalam tradisi Ma'arolo Lani Mala'apa di desa Pelauw sesuai fokus penelitian. 
Penelitian ini menggunakan pendekatan penelitian kualitatif karena akan mendeskripsikan secara terperinci serta mendalam hasil penelitian dengan menggunakan kata-kata dan bukan berupa angka.

Sumber data penelitian ini adalah folksong dalam tradisi Ma'arolo Lani Mala'apa, Maalani dan masyarakat desa Pelauw yang menguasai folksong dalam tradisi Ma'arolo Lani dengan keadaan sehat lahir dan batin. Hal itu berarti, subjek tidak mempunyai kelainan atau cacat, baik fisik maupun mental. Maalani pada umumnya tinggal di Desa Pelauw, Kecamatan Pulau Haruku Maluku Tengah. Dalam tradisi Ma'arolo Lani Mala'apa tidak adanya batas umur dan aturan yang mengatur untuk menjadi seorang Maalani.

Data penelitian ini adalah semua folksong dalam tradisi Ma'arolo Lani Mala'apa di Desa Pelauw. Dengan kata lain yang menjadi data penelitian ini adalah semua nyanyian rakyat yang dinyanyikan dalam upacara perkawinan adat di Desa Pelauw.

Teknik yang digunakan dalam penelitian Folksong dalam Tradisi Ma'arolo Lani Mala'apa di Desa Pelauw Kecamatan Pulau Haruku Maluku Tengah (Kajian Makna) adalah metode penelitian kualitatif dengan menggunakan teknik observasi, catatan lapangan, wawancara, dokumentasi, dan teknik terjemahan.

Teknik analisis penelitian Folksong dalam tradisi Ma'arolo Lani Mala'apa di Desa Pelauw Kecamatan Pulau Haruku Maluku Tengah (Kajian Makna) adalah teknik analisis data dengan memanfaatkan teori Miles and Huberman yang dimanfaatkan secara bersamaan, dimulai dari reduksi data, paparan data, verifikasi data, dan simpulan data.

Interpretasi data yang digunakan peneliti adalah content analysis karena penelitian ini akan dianalisis isi secara umum mengenai deskripsi karakteristik Folksong dalam Tradisi Ma'arolo Lani Mala'apa di Desa Pelauw Kecamatan Pulau Haruku Maluku Tengah (Kajian Makna).

PEMBAHASAN

Schleiermacher memahami hermeneutik sebagai 'seni memahami' (the art of understanding). Penerapan hermeneutik sangat luas, yaitu dalam bidang teologis, filosofis, linguistik maupun hukum. Pada dasarnya, hermeneutik adalah filosofis sebab merupakan bagian dari seni berpikir. Pertama-tama, ide yang ada di pikiran kita pahami, baru kemudian kita ucapkan. Inilah alasannya mengapa Schleiermacher menyatakan bahwa bahasa kita berkembang seiring dengan buah pikiran kita. Namun, bila pada saat berfikir kita merasa perlu untuk membuat persiapan dalam mencetuskan buah pikiran kita, maka pada saat itulah terdapat apa yang disebutnya the transformation of the original thought, and then explication also becomes necessary.

Menurut Schleiermacher, ada jurang pemisah antara berbicara atau berfikir yang sifatnya internal dengan ucapan aktual. Seseorang harus mampu mengadaptasi buah pikiran ke dalam kekhasan lagak ragam dan tata bahasa. Dalam setiap kalimat yang diucapkan, terdapat dua momen pemahaman, yaitu apa yang dikatakan dalam konteks bahasa dan apa yang dipikirkan oleh pembicara. Setiap pembicara mempunyai waktu dan tempat, kemudian bahasa dimodifikasi menurut kedua hal tersebut. Pemahaman hanya terdapat di dalam kedua momen yang saling berpautan satu sama lain itu. Baik bahasa maupun pembicaranya harus dipahami sebagaimana seharusnya. Menurut Schleiermacher, ada dua 
tugas hermeneutik yang pada hakikatnya identik satu sama lain, yaitu interpretasi gramatika dan interpretasi psikologis. Bahasa gramatikal merupakan syarat berpikir setiap orang. Sedangkan aspek psikologis interpretasi memungkinkan seseorang menangkap 'setitik cahaya' pribadi penulis. Oleh karenanya, untuk memahami pernyataanpernyataan pembicara orang harus mampu memahami bahasanya sebaik memahami kejiwaannya. Semakin lengkap pemahaman seorang atas sesuatu bahasa dan psikologi pengarang, akan semakin lengkap pula interpretasinya. Kompetensi linguistik dan kemampuan mengetahui seseorang akan menentukan keberhasilannya dalam bidang seni interpretasi.

Tugas hermeneutik menurut Schleiermacher adalah memahami teks sebaik atau lebih baik daripada pengarangnya sendiri dan memahami pengarang teks lebih baik dari pada memahami diri sendiri.

\section{Hermeneutika Psikologis}

Schleiermacher berpendapat bahwa seseorang tidak bisa memahami sebuah teks hanya dengan semata-mata memperhatikan aspek bahasa saja, melainkan juga dengan memperhatikan aspek kejiwaan pengarangnya. Seorang penafsir teks harus memahami selukbeluk pengarangnya. Pemaknaan folksong dalam tradisi Ma'arolo Lani Mala'apa dengan memperhatikan aspek kejiwaan pengarang terhadap karya sastra yang dihasilkan. Hal tersebut dapat terlihat pada data-data di bawah ini.

Mae-mae ina mae-mae ama Mae-mae hiti aruhaha Ihiu lahate lalolo (FMLM.A1.1)
Mari saudara saudariku Mari kita saling sayang menyayangi Persaudaran di atas segala-galanya

Komposisi pada data (FMLM.A1.1) mengandung maksud untuk memperjelas hubungan persaudaraan yang terjalin di antara orang Pelauw pada khususnya dan masyarakat Hatuhaha pada umumnya. Dalam pemahaman Islam, Hatuhaha terkait dengan proses perkawinan adat. Data (FMLM.A1.1) merupakan wejangan atau nasehat kepada kedua mempelai agar dapat menghormati dan menghagai orang tua dan saudara-saudaranya. Komposisi merupakan proses penciptaan folksong dalam tradisi Ma'arolo Lani Mala'apa di Desa Pelauw. Tradisi Ma'arolo Lani Mala'apa adalah salah satu dari sekian banyak kesenian tradisional Hatuhaha yang terdapat di Desa Pelauw Kecamatan Pulau Haruku Maluku Tengah. Ma'arolo Lani merupakan seni mendendangkan tembang folksong secara lisan dalam wujud penyanyian diiringi musik tipa (gendang). Komposisi pada data (FMLM.A1.1) akan berbeda jika disandingkan dengan penggalang lagu berikut yang telah di adopsi ke dalam nyanyian pop.

\section{Mae-mae ina mae-mae ama Mae rutu maningkamu tine Rutu maningkamu Hatuhaha lookaeya}

\author{
Mari saudara saudariku \\ Mari kumpul basudara \\ Mempererat ikatan persaudaraan \\ Orang Hatuahaha semua
}

Penggalang lagu tersebut menunjukkan komposisi penambahan kalimat yang dilakukan oleh para seniman (penyanyi/pencipta lagu) 
terhadap nyanyian dasar yang terdapat pada folksong dalam tradisi Ma'arolo Lani Mala'apa. Pada penggalang lagu tersebut, dapat diamati bahwa seseorang dapat melakukan improvisasi dengan cara menambahi kalimat lebih dari yang seharusnya ia tambahi. Hal tersebut sangat berguna untuk memperluas, memperjelas, dan mempertegas makna yang ia sampaikan agar lebih dipahami oleh audiens. Hal tersebut sangat lumrah ditemui dalam prosesi tradisi lisan. Agar pesan dapat tersampaikan dengan baik, terkadang seseorang penembang melakukan penambahan-penambahan untuk mempertegas dan memperjelas kalimat-kalimat yang sebelumnya ia sampaikan. Hal ini dapat terlihat pada data berikut juga.

Tompe aeee lala tompel aeee Lala nau ahia lala tompe aee Lala tompe aeee (FMLM.A1.2)
Tompe, jalan yang jelek Jalan yang jelek, jalan tompe Jalanan yang jelek jalan tompe

Data (FMLM.A1.2) memiliki komposisi yang serupa dengan data (FMLM.A1.1) karena sama-sama terdiri atas tiga larik dan tiap-tiap lariknya diakhiri oleh bunyi vokal. Lewat syair-syairnya yang jenaka dan lirik lagunya yang menarik, puisi lagu atau folksong dalam tradisi Ma'arolo Lani Mala'apa mampu memberikan fungsi rekreatif, hiburan yang segar untuk mengajak pendengar bersenang-senang namun sekaligus di dalamnya terkandung nilai-nilai yang bermanfaat. Data (FMLM.A1.2) merujuk pada makna 'jika memasuki rumah tangga harus dengan segala kebaikan'. Memulai hidup yang baru pasti banyak cobaan dan halangan namun semuanya akan baik-baik saja jika dilandaskan dengan perasaan mencintai, keikhlasan, kesabaran, dan sikap untuk selalu melakukan kebaikan tentu semuanya akan dapat dilewati dan indah dengan sendirinya. Berpikir positif tentang cobaan yang berikan Tuhan, karena setiap cobaan yang datang tidak akan pernah melebihi batas kemampuan umatnya.

Data (FMLM.A1.1) dan data (FMLM.A1.2) merupakan dua dari sekian data dalam folksong dalam tradisi Ma'arolo Lani Mala'apa di Desa Pelauw Kecamatan Pulau Haruku untuk menunjukkan bahwa folksong ini memiliki komposisi dalam hal penciptaannya, dipertunjukkan dalam setiap ritual perkawinan adat dan diwariskan secara langsung maupun tidak langsung kepada seluruh masyarakat Pelauw.

Suka ite ruwa i tuhu meito tala'e Suka ite ruwa i rowa iwano taloto Suka ite ruwa i teti tomolo talae Wa'a ruwai ha'a wano (FMLM.A1.3)
Cinta kita mampu menyelami lautan Cinta kita sanggup mendaki gunung Cinta kita tegar membela bamboo Untuk cinta kita setinggi gunung

Pada data (FMLM.A1.3), jelas terlihat adanya hubungan berdasarkan susunan kata. Terdapat hubungan klausa subyek-predikat dan sebab akibat. Di samping itu juga ada hubungan sintaksis lainnya, yakni ditemukannya klausa usaha-hasil yang tersirat pada folksong dalam tradisi Ma'arolo Lani Mala'apa. Data (FMLM.A1.3) menceritakan tentang perasaan saling mencintai dua insan yang tidak di restui orang tua, namun mereka tetap mempertahankannya walaupun 
banyak rintangan dan halangan serta mengandung makna yang tersirat dan mengandung nilai-nilai luhur yang baik.

Yau mangaku ina'u pamata au eya Saya bersedia dibunuh oleh Ibuku Yau mangaku ama'u pamata au eya Saya bersedia dibunuh oleh Bapakku Yau mangaku lopua wa'a hono'u eya Saya bersedia dipedangi di leher Tagaleke suka ite rua Semuanya karena cinta kita berdua (FMLM.A1.4)

Pada data folksong, terlihat adanya hubungan sebab akibat. Pada larik pertama, "yau mangaku ina' 'u pamata au eya," merupakan folksong yang memiliki hubungan konstruksi lengkap dan elips. Dikatakan memiliki konstruksi lengkap dan elips karena terdiri atas subjekpredikat-objek-keterangan begitu pula dengan larik yau mangaku ama'u pamata au eya, yau mangaku lopua wa'a hono'u eya, serta menunjukan adanya hubungan sintaksis lainnya yakni ditemukan klausa usaha-hasil. Data (FMLM.A1.4) mengandung maksud pengorbanan cinta. Dengan demikian, folksong dalam tradisi Ma'arolo Lani Mala'apa dapat mewakili ungkapan perasaan seseorang secara tersirat.

\author{
Hio hio ase hio hio \\ Hio hoo hio ase hiya hiyo \\ Yole yole ase yole yole \\ Yole yole yole ase yole yole (FMLM.A1.5)
}

Pada data (FMLM.A1.5), dapat diamati bahwa terdapat pemakaian unsur bunyi yang sama pada setiap akhir larik yakni pada kata hio pada akhir larik pertama dan hio pada akhir larik kedua. Hal ini juga berlaku pada larik ketiga dan keempat yang terdapat persamaan kata di akhir lariknya yaitu pada kata yole. Folksong tersebut merupakan hasil improvisasi seseorang Maalani dalam membentuk nikomposisi skematis. Maalani dengan sengaja memilih unsur bunyi yang sama dengan menggunakan berbagai variasi kata untuk memperindah bunyi dalam memperdendangkan folksong tersebut. Data tersebut merujuk pada maksud memberi nasehat kepada kedua mempelai agar segala sesuatu yang kelak terjadi dalam rumah tangga mereka harus dapat diselesaikan secara baik-baik dan secara kekeluargaan. Pada data tersebut, terdapat juga formula pengulangan kalimat identik pada folksong dalam tradisi Ma'arolo Lani Mala'apa dengan mengulangulang kata hio, ase, dan yole yang dipahami oleh masyarakat Pelauw sebagai salah satu nyanyian. Hal tersebut berfungsi untuk menegaskan kembali nasehat-nasehat dari orang tua dan para leluhur agar tetap menjaga dan memlihara rumah tangga mereka dengan baik. Dengan kata lain, dapat pula diartikan 'mohon doa restu'. Para penembang atau Maalani bermaksud mewakili kedua mempelai memohon doa restu kepada seluruh masyarakat yang hadir dalam prosesi perkawinan mereka agar prosesinya dapat berjalan dengan lancar tanpa mengganggu masyarakat setempat yang sedang beristirahat.

Lebe Lessya iya Latua Ronesina Imam Hatuhaha iya Monia Makakuku Lebe Waele kura Lebe Wakane Hatuhaha I toweya

(FMLM.A1.6)
Ulama Lessy adalah Raja Ronesina Imam Hatuhaha adalah Monia Makakuku Ulama wael dan Ulama Wakan Itulah Hatuhaha 
Data (FMLM.A1.6) mengungkapkan bahwa di dalam keseluruhan runtutan lariknya mengandung formula pengulangan makna. Larik pertama "Lebe Lessya iya Latua Ronesina" hingga larik keempat "Hatuhaha I toweya" merupakan satu kesatuan makna dan maksud. Hal ini menjelaskan bahwa pada larik pertama menyebutkan kembali kepada orang yang sama. Begitu pula yang terjadi pada larik kedua dan ketiga, serta larik keempat yang menjelaskan secara utuh hubungan semuanya, yakni Lebe lesya, Imam Hatuhaha, Lebe Waelo dan Lebe Wakan merupak keempat aulia/ulama yang mempersatukan Hatuhaha. Penyair dalam tembang tersebut mencoba menjelaskan bahwa sejarah itu penting untuk diketahui oleh generasi penerus. Oleh karena itu, perjalanan sejarah ini pun dinyanyikan dalam tradisi Ma'arolo Lani Mala'apa agar secara langsung dapat dipelajari oleh generasi muda. Setiap lariknya menjelaskan tentang kepemimpinan. Kepemimpinan mereka mewakili setiap daerah yang mereka pimpin serta gelar masingmasing pemimpin. Hal ini juga menjelaskan secara langsung bahwa hakikatnya keempat pemimpin ini memilki ikatan persaudaraan dan disatukan dalam payung maningkamu yaitu Hatuhaha.

Taha yukarana leuwa iny manggahina Yukarana leuwa iny budi adatea

Yukarana leuwa iny budi adato

Suwe Sopa iny kuruhajia

(FMLM.A1.7)
Tak ada yang secantik dirimu Yang berbudi pekerti luhur sepertimu Yang berbudi adat sepertimu Sesuai ajaran orang tua

Pada data (FMLM.A1.7), terlihat pengulangan kata yang terdapat dalam larik yang berbeda yakni pada kata 'yukarana leuwa iny' yang mengalami pengulangan kata pada larik kedua dan larik ketiga, dan kata 'budi' pada larik kedua diulang lagi pada larik ketiga. Data (FMLM.A1.7) memiliki kemiripan dengan pantun karena larik-larik itu panjangnya kurang lebih sama dan batas sintaksis berada ditengahtengahnya. Penyair dalam folksong tersebut mencoba menjelaskan serta menegaskann kembali bahwa adat; adab; moral itu sangat penting oleh seorang perempuan yang diturunkan secara langsung oleh garis keturunannya, yang tidak hanya cantik tetapi baik, sopan, dan ramah. Pada cerita dalam nyanyian ini mengisahkan tentang perjalanan hidup, prinsip hidup pengantin perempuan yang berbudi pekerti sesuai ajaran kedua orang tua.

Tupa duniaeya rua rua syi soi

Turu kuburoti isyai isyai turu

Ai ihi paha lekalehano

Kou e molon kiri kiri

(FMLM.A1.8)
Hidup di dunia saling berpasangan Meninggal dunia sendiri dikuburkan Papan/batu nisan; papan penutup mayat Lihat dalam kegelapan

Pada data (FMLM.A1.8), terlihat dengan jelas adanya pengulangan kata yang sama dalam satu larik. Seperti pada larik pertama, terdapat kata 'rua rua'. Pada larik kedua terdapat pengulangan kata yang sama, yakni pada kata 'isyai isyai', pada kata 'turu' pada awal larik kedua diulang lagi di akhir larik yang sama. Pada larik ketiga terdapat pada kata 'kiri kiri'. Folksong dalam tradisi Ma'arolo Lani Mala'apa ini mengandung makna segala sesuatu yang kita perbuat adalah baik maka dikemudian hari akan mendapatkan baik sebaliknya yang kita perbuat 
tidak baik maka akan menuai hal yang tidak baik. Hal tersebut dapat menjadi pesan bagi warga agar senantiasa melakukan hal-hal terbaik dalam hidup. Ketika hidup di dunia berbuat yang baik untuk sesama, namun ketika menghadap sang pencipta masing-masing menghadap. Di alam kubur yang terlihat hanya gelap gulita dan hanya amal ibadah yang menjadi penerang. Data tersebut secara tidak langsung merupakan bentuk sanksi sosial bahwa segala sesuatu yang kita perbuat adalah baik maka dikemudian hari akan mendapatkan baik sebaliknya yang kita perbuat tidak baik maka akan menuai hal yang tidak baik. Hal tersebut dapat menjadi pesan bagi warga agar senantiasa melakukan hal-hal terbaik dalam hidup. Ketika hidup di dunia berbuat yang baik untuk sesama, namun ketika menghadap sang pencipta masing-masing menghadap, di alam kubur yang terlihat hanya gelap gulita dan hanya amal ibadah yang menjadi penerang.

Le le le le iyo iyo wara e

Limbia hatua heri teuno nariae Tewa kei nahu hatua le'I wone Inahu eru sialana teuno

Suka kura ing birahi o o (FMLM.A1.9)
Le le le iya

Perasaan yang tak terbendung

Tak tahu kemana rasa ini kan pergi

Dibiarkan begitu saja

Ikuti keinginannya sendiri (egois)

Data (FMLM.A1.9) mengisahkan tentang perjalanan pengantin perempuan dari rumahnya menuju rumah mempelai pria. Setiap pertemuan pasti ada perpisahan, namun perpisahan yang dimaksudkan dalam Lani pada data (FMLM.A1.9) tersebut adalah pelepasan hak dan tanggung jawab dari kedua orang tua mempelai perempuan untuk dibebankan kepada calon suaminya. Tanggung jawab ayah mempelai perempuan untuk menanggung segala dosanya secara otomatis berpindah kepada sang suami ketika ikrar janji suci atau ijab qabul disahkan oleh penghulu dan pihak KUA. Data (FMLM.A1.9) tergolong folksong yang bersifat primer karena penyebarannya hanya melalui lisan. Dengan demikian, termasuk sastra lisan versi lisan. Adapun data yang termasuk versi lisan dan versi tulisan adalah sebagai berikut.

Eta putih mala loko notalae e

Turua wala wahi nunua weta-wetao

Ole Soe soe putia yau kihu ee

Hasa lanito nunua riko hale sawa o

(FMLM.A1.10)
Asalnya manusia adalah tak punya Orang kaya selalu Membanggakan diri Semakin kaya akan semakin sombong kita Jika meninggal, harta tidak dibawa

Data (FMLM.A1.10) mengisahkan tentang sikap mau bersyukur, kerendahan hati, sikap tidak sombong, dan tidak bangga dengan harta yang miliki. Setiap anugerah dan nikmat yang diberi sang Illahi adalah titipan untuk mahkluknya. Diharapkan dengan nikmat dan anugerah itu manusia senantiasa bersyukur, selalu rendah hati kepada sesama. Ketika seseorang meninggal, ia tidak membawa harta bendanya bersama melainkan amal ibadah. Data (FMLM.A1.10) ini tergolong sastra lisan yang bersifat sekunder dan primer karena folksong peyebarannya melalui lisan dan juga telah ditekskan, sudah ada dalam bentuk tertulis meskipun penciptanya atau pengarangnya sampai saat ini tidak ada yang mengetahuinya. 
Ai pasa loti epa suri-suri

Kisa yaka koti au rolonea

Sue gurua syi janji

(FMLM.A1.11)
Ilmu itu sangat bermanfaat

Diajarakan dengan kaidah dan metode

Sesuai yang dipesan oleh para Guru

Data tersebut menunjukkan nilai kepatuhan terhadap aturan, ajaran, dan petunjuk hidup yang telah diajarkan oleh para orang tua dan guru kepada generasi-generasi penerus. Pada data (FMLM.A1.11), jelas tergambarkan dari pengertiannya yakni 'ilmu itu sangat bermanfaat, diajarkan dengan kaidah dan metode sesuai dengan pesan para guru dan leluhur'. Pembahasan serupa dilakukan secara struktural sederhana, namun memilki makna yang cukup dalam guna mencerminkan nilai etik luhur serta akan memperkaya keluhuran budi. Dengan demikian, nilai pendidikan yang dapat dijadikan pedoman hidup oleh masyarakat khususnya bagi para generasi muda sebagai generasi penerus bangsa ialah (1) memiliki sikap patuh terhadap ajaran leluhur, (2) menyadari pentingnya ilmu, (3) memperhatikan kaidah dan cara-cara yang yang benar dalam menerapkan setiap aturan.

Laturonea yale amam he'e wone Makaku yale inam he'e wone Yale seiya kewa rua nalasi

Koti meito talae

(FMLM.A1.12)
Laturone Bapakmu dari mana Makakuku ibumu dari mana Siapa yang mengetahui nama keduanya Bisa mengetahui rahasia lautan

Data tersebut tidak hanya dapat dimaknai secara sturktural bahasa semata namun akan lebih tepat jika dimaknai secara psikologis atau kejiawaan dari nyanyian tersebut. Hal ini bagi masyarakat setempat mengandung makna yang lebih luas dan mendalam yakni 'barang siapa mengetahui asal bapakmu, ibumu, kakek, nenek dan garis keturunanmu dengan baik maka engkau dapat mengetahui dan memahami diri dan hubungan persaudaraan yang ada padamu'. Dengan demikian pada data (FMLM.A1.12) secara langsung kita menjelaskan asal muasal atau identitas kita. Tiap masyarakat memilki latar belakang budaya dan bahasa yang berbeda, puisi-puisi lagu dan nyanyian-nyanyian yang biasa didendangkan dan atau disenandungkan cocok untuk konsumsi kejiwaan, jiwa akan terangsang mengikuti aliran bunyi dan gerak hingga dapat mengambil nilai-nilai yang ada didalamnya guna mempererat ikatan persaudaraan dan rasa solidaritas. Hal tersebut dapat pula terlihat pada berikut.

Mae mae ina mae mae ama Mae mae hiti aruhaha Ihiu lahate lalolo (FMLM.A1.1)
Mari saudara saudariku Mari kita saling sayang menyayangi Menjaga persaudaran di atas segala-galanya

Data (FMLM.A1.1) mengandung makna dan maksud yang serupa dengan data (FMLM.A1.12) karena secara langsung menjelaskan adanya hubungan persaudaraan antar orang-orang yang ada di desa Pelauw dan sekitarnya untuk tetap saling menghormati, saling menyayangi, dan mengumandangkan bahwa persaudaraan ini ada dan akan selalu menjadi dasar pemikiran mereka dalam berbuat dan 
bertindak. Menunjukkan bahwa segala sesuatu dapat dibicarakan secara kekeluargaan.

Yomone masawana yomone

Yombadiya Masa Masawana Yomone

Masawana yomoneya

(FMLM.A1.13)
Oma e, orang yang menikah di Oma

Yang menikah di Oma

Menikah di Oma

Pada data (FMLM.A1.13), keindahan puisi-lagu atau nyanyiannyanyian dapat dilihat dari segi kesastraan dan lagu yang mendukungnya sedangkan jika dimainkan dengan iringan gamelan (musik tradisional) atau musik modern keindahannya bertambah dengan bunyi musik yang mengiringinya itu. Perpaduan antara keindahan syair, lagu, dan musik pengiring akan menghasilkan bunyi yang bernilai estetis lebih lengkap dan tentunya berpengaruh terhadap kejiwaan. Secara struktur sintaksis, data tersebut memiliki arti seperti yang telah dijabarkan di atas. Namun, ketika peneliti mencoba menggali makna lain dari data (FMLM.A1.13), terungkap bahwa pada data tersebut mengandung makna yang lain yakni 'perkawinan itu adalah perkawinan antar dua keluarga besar, perkawinan yang pada dasarnya sakral dan intim. Hubungan dalam perkawinan ini patut dijaga dan dijunjung tinggi kehormatan dan nilai yang esensial dari perkawinan itu sendiri sehingga pasangan ini dapat menjadi keluarga yang sakinah, mawadah, dan warrahmah.

Singgaluano haka singgaluano

Haka kotu lebea, Lebea singga luano

Singgaluano e

(FMLM.A1.14)
Singgasana terbuka singgasana

Bertemu Lebe di singgasana

Oo singgasana....

Lewat syair-syairnya yang jenaka dan lirik lagunya yang menarik, puisi lagu atau folksong dalam tradisi Ma'arolo Lani Mala'apa mampu memberikan fungsi rekreatif, hiburan yang segar untuk mengajak pendengar bersenang-senang namun sekaligus di dalamnya terkandung nilai-nilai yang bermanfaat. Setiap ritual perkawinan yang dilaksanakan di Desa Pelauw, folksong-folksong ini selalu didendangkan meskipun bagi sebahgian anggota masyarakat tidak memahami betul makna dan maksud dari nyanyian-nyanyian ini kata per kata. Tetapi, lewat lirik lagunya, mereka dapat memperoleh hiburan yang menyenangkan sekaligus membangkitkan perasaan keindahan. Data (FMLM.A1.14) dapat dimaknai bahwa makna esensial dari folksong pada data adalah kesiapan mempelai wanita dan mempelai pria menyongsong hidup yang baru sebagai pasangan suami istri, memasuki rumah tangga yang baru dengan harapan yang baru, direstui oleh orang tua kedua belah pihak, tetuah adat, dan para leluhur yang telah diikrarkan lewat janji suci di depan para penghulu (pihak KUA) dan telah disahkan secara adat istiadat Desa Pelauw dan sah secara hukum agama yang berlaku di Indonesia.

Kupa waa kadera sane Kura seiya kupa pamanau Ei mori pamanau ei morie (FMLM.A1.15)
Duduk di satu kursi bersama duduk makan Tak usah berbicara sambil makan 
Permainan kata dan struktur sintaksis perlu diperhatikan dalam proses penciptaan karya sastra. Di dalam proses penciptaannya, tercurahkan perhatian pengarang pada masalah kekuatan jiwa estetis yang membangun nurani sebuah karya sastra. Untuk memahami jiwa folksong ma'arolo lani mala'apa pada data (FMLM.A1.15), peneliti tidak memaknainya kata per kata melainkan keseluruhan larik sebagai satu kesatuan yang kompleks. Data (FMLM.A1.15) tersebut mengandung makna 'kedudukan (tahta) bukanlah sesuatu yang perlu disombongkan melainkan dengan jabatan itu kita harus bertanggung jawab, berbagi untuk sesama, ketika membantu janganlah diceritakan kepada orang lain.

Ehe yapapeiya yapa wari'e lau

Leu mane kosa niki mea

Leu mane kosa nikimea

Suwe mahua rana nama

(FMLM.A1.16)
Jangan menginap di hutan

Pulanglah dan sikat gigi

Pulanglah dan sikat gigi

Sesuai amanah sebelumnya

Selain lewat permainan kata dan struktur sintaksis, keindahan bahasa itu juga diperoleh melalui pendayagunaan berbagai bentuk perbandingan, teka-teki, peribahasa, dan perumpamaan. Hal tersebut tampak pada data (FMLM.A1.16). Data tersebut mengandung makna yang tersirat dan mengandung nilai-nilai luhur yang baik. Pada data (FMLM.A1.16), jelas tampak adanya bentuk perumpamaan yang mengisyaratkan bahwa setelah menikah dan hidup di perantauan jangan terlalu lama, harus ingat kampung halaman sesuai amanah para tetuah.

\section{Hermeneutika gramatikal}

Hermeneutika gramatikal adalah penafsiran yang didasarkan pada analisis bahasa. Karena itu, seorang penafsir teks harus menguasai aspek-aspek bahasa. Semakin dia menguasai bahasa, semakin baik penafsirannya. Bagi Schleiermacher, hermeneutika gramatikal ini merupakan sisi obyektif penafsiran. Pemaknaan folksong dalam tradisi Ma'arolo Lani Mala'apa di Desa Pelauw dengan memperhatikan aspek kebahasaan dapat terlihat pada data-data di bawah ini.

Rie rie bangsa heu heu bangsa e e Sala aha bangsa kappa ina yoi Bangsa bangsa hatu e kuhu la meito Bangsa paal lema nanu (FMLM.A2.17)

\author{
Mencari jodoh memilih-milih \\ Tidak sembarang kita memilih \\ Jodoh yang menjerumuskan \\ Jodoh itu akan menghanyutkanmu
}

Pada data (FMLM.A2.17), nampak dengan jelas pada akhir setiap lariknya terdapat pengulangan bunyi vokal meskipun tak sama bunyinya yakni bunyi $e$, $i$, $o$, dan bunyi $u$. Data (FMLM.A2.17) mengisahkan tentang perjalanan pencarian pasangan hidup. Menentukan jodoh yang tepat memang sulit, namun dengan mengetahui garis turunan seseorang dapat membantu memilah dan memilih orang yang tepat sebagai pasangan hidup kita.

Kasituria inai rua Kasituria Inai rua

Wale wale inya leuwa

Wale inya leuwa e (FMLM.A2.18) 


\author{
Hio hio ase hio hio \\ Hio hoo hio ase hiya hiyo \\ Yole yole ase yole yole \\ Yole yole yole ase yole yole (FMLM.A1.5)
}

Data (FMLM.A2.18) mengalami pengulangan suku kata '-wa' pada larik kedua kata 'leuwa' bertemu dengan suku kata awal ' $w a-$ ' pada kata 'wale' larik ketiga. Data (FMLM.A1.5) menunjukan adanya pengulangan kata pada akhir larik yang akan diulangi pada awal larik berikutnya, seperti pada kata ' hio' pada akhir larik pertama yang diulangi lagi pada larik kedua kata 'hio' di awal larik kedua.

Suka ite ruwa wainsyatieya Cinta kita berdua begitu kuat

Murane kuruhajia taha suka saeya Mengapa orang tua kita tidak suka

Kuruhaji taha suka saeya Orang tua tidak suka

Tati suwe syene ma'i Ikuti kemauan mereka akan lebih baik

(FMLM.A2.19)

Data (FMLM.A2.19) termasuk dalam tema percintaan. Permainan bunyi pada kata-kata membangkitkan aspek persajakan dan irama yang indah terdengar. Data (FMLM.A2.19) mengandung makna yang tersirat dan mengandung nilai-nilai luhur yang baik, menceritakan tentang perasaan saling mencintai dua insan yang tidak direstui orang tua. Perasaan itu harus diabaikan bahkan terlupakan karena rasa hormat kepada orang tua. Hal serupa juga terlihat pada berikut.

Yau mangaku tupa buiya wa'a saparua Yau mangaku gantong wa'a hale kota Yau mangaku ranteya wa'a honou'o Suwe suka ite ruwa

(FMLM.A2.20)
Saya bersedia masuk penjara di Saparua Saya bersedia digantung di kota Ambon Saya bersedia dijerat/dirantai di leher Sesuai cinta kita berdua

Data (FMLM.A2.20) menceritakan tentang perasaan saling mencintai, sikap mau berkorban kepada kekasih, bahkan ketika maut menjemputpun mereka siap.

Imane manisa buji rahatala Horomate ehe niate barobah Niate barobah rusak badango Lauw woria kupu susah (FMLM.A2.21)
Iman yang benar itu mempercayai Allah Berpegang teguh jangan berubah Niat berubah merusak akidah Dikemudian hari akan mendapat bencana

Pada data (FMLM.A2.21), permainan kata dan struktur sintaksis perlu diperhatikan dalam proses penciptaan karya sastra. Di dalam proses penciptaannya, perhatian pengarang tercurah pada masalah kekuatan jiwa estetis yang membangun nurani sebuah karya sastra. Data (FMLM.A2.21) mengandung makna yang tersirat dan mengandung nilai-nilai luhur yang baik, yaitu keyakinan kepada Allah Swt. Segala sesuatu yang terjadi di dunia, hari ini dan hari esok, yang baik dan yang buruk itu sudah menjadi ketentuan Allah Swt. Untuk itu, manusia harus selalu bersyukur dan bertawakal serta ikhlas dengan segala macam cobaan yang menimpah. Pada dasarnya, perbuatan yang baik akan mendapatkan balasan yang baik dan sebaliknya perbuatan yang buruk 
akan mendapatkan balasan yang buruk pula. Dengan demikian, untuk memahami jiwa folksong Ma'arolo Lani Mala'apa pada data (FMLM.A2.21), peneliti tidak memaknainya kata per kata melainkan keseluruhan larik sebagai satu kesatuan yang kompleks, mengandung maksud untuk menasehati atau sebagai petunjuk hidup.

Abudakelo wala rombahingo

Rombahinge abudakel ngerombange

Abu-abu dakel waelo rombahiyang o eee

(FMLM.A2.22)

Data (FMLM.A2.22) mempunyai maksud jenaka karena tidak memiliki struktur sintaksis atau mempunyai batas sintaksis. Data tersebut hanya terdiri atas dua sampai tiga kata yang hanya diulang-ulang dan memiliki keindahan bahasa yang diperoleh lewat pendayagunaan berbagai bentuk perbandingan ataupun teka-teki seringkali dibarengi dengan ekspresi folklor. Permainan adalah gerak yang sering menyertai lagu dalam tradisi Ma'arolo Lani Mala'apa. Lewat permainan bunyi pada kata-kata terpilih akan dapat dibangkitkan aspek persajakan dan irama puisi yang menyebabkan puisi menjadi indah dan melodis, bersifat riang dan mencerminkan nilai etik luhur.

Mata teleto hau mata teleto

Rawa wiri-wiri a

Hau mata teleto, Mata teleto $e$

(FMLM.A2.23)
Wangi, berbau wangi

Berlari sambil kipasi

Berbau wangi, wangi

Data (FMLM.A2.23) dijadikan untuk menggambarkan fungsi ketiga juga dapat dijadikan gambaran fungsi keempat. Kutipan tembang tersebut mengisyaratkan bahwa sebesar apapun kekuatan yang dipergunakan untuk keburukan atau kejahatan maka cepat atau lambat kekuatan itu akan musnah dan dikalahkan oleh kebaikan. Kutipan pada data (FMLM.A2.23) tidak mengandung arti yang sebenarnya tetapi mengandung maksud sindiran bahwa sebagai manusia jangan suka bermulut manis, menebarkan informasi-informasi yang palsu, bergosip kesana kemari sebab apa yang dilakukan dapat menimbulkan kesalahpahaman dan ketidaknyamanan hidup bermasyarakat.

Dalam kehidupan bermasyarakat, seringkali kita temui perilakuperilaku masyarakat yang menyimpang dari norma-norma yang berlaku. Banyak fenomena yang terjadi di dalam masyarakat, seperti contoh yang berkembang pada saat ini ialah saat menjamurnya konflik perebutan kekuasaan oleh pemerintah maupun masyarakat setempat yang sering mempertontonkan ketidakadilan dalam melakukan pembelaanpembelaan terhadap seseorang yang dianggap berkuasa walaupun seseorang yang dibela tersebut berada dipihak yang salah. Adanya budaya lokal seperti tradisi ma'arolo lani mala'apa dapat digunakan masyarakat sebagai media untuk mengkritisi perilaku maupun kebiasaan menyimpang yang tidak sesuai dengan norma-norma yang berlaku.

Dzikire karompe rumah sigito

Rumasigito ee, Dzikire karompe

Rumasigito, Rumasigito weya

(FMLM.A2.24) 
Data (FMLM.A2.24) mempunyai maksud jenaka. Permainan adalah gerak yang sering menyertai lagu dalam tradisi Ma'arolo Lani Mala'apa. Lewat permainan bunyi pada kata-kata terpilih, dapat dibangkitkan aspek persajakan dan irama puisi yang menyebabkan puisi menjadi indah dan melodis. Data (FMLM.A2.24) bersifat riang dan mencerminkan nilai etik luhur. Oleh karena itu, pengungkapan nyanyian atau puisi lagu sejenis bagi masyarakat dan generasi muda akan memperkaya keluhuran budi.

\section{Bebek innai mata wana kunu pau' Induk bebek begadang membakar sagu Yale seiya taria ruma murin yea Siapa kamu di luar sana Nusu male yane hua Masuklah kita makan pinang}

(FMLM.A2.25)

Selain lewat permainan kata dan struktur sintaksis, keindahan bahasa juga diperoleh melalui pendayagunaan berbagai bentuk perbandingan, teka-teki, peribahasa, dan perumpamaan. Seperti yang tampak pada data (FMLM.A2.25), kata bebek innai tidak mengandung arti induknya bebek melainkan kaum perempuan. Data (FMLM.A2.25) jelas memperlihatkan bahwa ketika kaum perempuan begadang membakar sagu dalam jumlah banyak mereka tidak mengeluh sama sekali, melainkan mereka merasa senang dan terhibur dengan memanggil orang lain yang berada di luar rumah untuk masuk dan bersama-sama makan pinang.

\section{Habareke tihu pikale kanama Sei kewa wae male hale leu e Wae male wae tahina pinano Ekala kihi haita pessy \\ Kabar Telaga Pikal kembali tergenang Siapa yang tahu air kembali Air Mengalir, air perempuan Mengalir sepanjang pelabuhan Pessy} (FMLM.A2.26)

Tihu pikaloti Latu Ronesina Telaga Pikal itu Raja Pelauw Tihu Sahamonia, monia makakuku Telaga Sahamoni itu Raja Rohomoni Rua syi haheu loto batino Taha sai he'u sa (FMLM.A2.27) Mereka berdua saling bekerja Mereka saling melengkapi

Data (FMLM.A2.26) dan (FMLM.A2.27) memiliki kemiripan dengan pantun karena larik-larik itu panjangnya kurang lebih sama dan batas sintaksis berada ditengah-tengahnya. Permainan bunyi pada katakata terpilih akan dapat membangkitkan aspek persajakan dan irama yang menyebabkan puisi-lagu atau nyanyian ini menjadi indah dan melodis. Data (FMLM.A2.26) dan (FMLM.A2.27) merupakan folksong yang menceritakan sejarah perjalanan para leluhur, memiliki makna yang lebih hakiki dalam ritual perkawinan. Secara theologhy Islam Hatuhaha, kata telaga pikal dan atau tihu pikal merujuk kepada laki-laki dam mengandung arti sperma, sedangkan kata wae tahina dan atau tihu salamonia merujuk kepada perempuan diartikan sebagai rahim untuk menampung sel sperma, mengandung makna perjalanan sperma bertemu sel telur dan mendiami sebuah tempat yaitu rahim. Kehadiran seorang perempuan dalam kehidupan seorang laki-laki, untuk saling melengkapi. 
Kebersamaan dan keterikatan mereka mampu melahirkan keturunanketurunan yang berguna bagi sesama.

Upu Awal Adam ikita suwe lotomena

Upu Rihia hale ikutumurinyi eaa

Ruasi hehe aisyi wa'a kupang puti'ooo

Ehala nalaele duniae

(FMLM.A2.28)
Nabi Adam berjalan di depan

Kakek Rihia berjalan dibelakangnya Mereka berdua berpijak di suatu tempat Yang dinamakan dunia

Data (FMLM.A2.28) menceritakan tentang sejarah turunnya nabi Adam As. bersama seorang pengikutnya. Mereka diturunkan ke bumi untuk melaksanakan perintah Allah Swt. yakni menjadi khalifah dimuka bumi. Namun, jika dimaknai secara theologhy Islam Hatuhaha dalam kaitannya dengan ritual perkawinan adat, akan mengandung arti yang berbeda, yakni proses kelahiran seorang bayi atau anak dari dalam rahim hingga melihat dunia. Dalam proses persalinan, ketika bayi ini dikeluarkan, akan diikuti oleh ari-arinya atau biasanya oleh masyarakat Pelauw di sebut lahan. Lahan ini biasanyanya diartikan sebagai saudara si bayi (kakaknya).

Hitua po iya Hatuahahai Yuma

Ehenala Ruhua si malatou

Ruhua simalatou yasalea

Hilangiya ka horomate

(FMLM.A2.29)
Orang Hitu bisa, tapi Hatuhaha lebih bisa Jangan sampai orang Luhu melihat Mereka melihat ke pasar kita Hilanglah kehormatan kita

Data (FMLM.A2.29) menggambarkan sikap mau berusaha dan bekerja keras. Persaingan dalam dunia kerja memang selalu ada, namun dituntun agar saling menghormati dan menghargai sesama. Dalam perkawinan, diharapkan suami istri dapat bekerja sama untuk mencukupi kebutuhan keluarga, menjamin pendidikan dan masa depan anakanaknya, serta melakukan hal-hal terbaik guna menjaga hubungan yang baik dengan keluarga besar, tetangga, dan masyarakat. Agar tidak kehilangan rasa hormat orang lain, kita harus saling menghormati dan menghargai sesama.

Bahasa gramatikal merupakan syarat berpikir setiap orang. Untuk memaknai setiap folklore, diperlukan interpretasi. Interpretasi ini berbeda antara penafsir yang satu dengan penafsir yang lain. Memaknai folklor juga tidak bisa hanya didasarkan pada struktur bahasa semata, melainkan perlu memperhatikan aspek psikologis, sosiologis, dan aspek budaya masyarakat yang diteliti. Folksong dalam tradisi Ma'arolo Lani Mala'apa mengandung makna yang hakiki dan sangat sakral, bahkan sebagian besar anggota masyarakatnya pun tidak bisa mengartikan dan memaknainya. Kesakralan Lani-Lani atau nyanyian-nyanyian ini terbukti dengan tidak diungkapkannya makna Lani tersebut secara langsung maksudnya tetapi melalui perumpamaan, sindiran, perbandingan maupun dalam bentuk teka-teki. Bentuk-bentuk ini menekankan aspek pragmatis folklore. Sekecil apapun folklor itu akan ada manfaatnya bagi yang percaya. Memuat logika folklor pada taraf prapemikiran serta pemaknaannya ini pun memiliki tujuan, yakni merujuk pada aspek pelestarian dan upaya perlindungan folklor itu karena menjadi milik kolektif. Jika terjadi sesuatu menyangkut folklor 
itu, pemiliknya rela berkorban. Hal ini tidak berarti folklor kurang beralasan, melainkan tetap ada alibi yang jelas dibalik karya tersebut.

SIMPULAN

Berdasarkan analisis yang telah dilakukan dapat disimpulkan bahwa makna folksong dalam tradisi Ma'arolo Lani Mala'apa di Desa Pelauw Kecamatan Pulau Haruku Maluku Tengah ditemukan ada dua, yaitu (1) hermeneutika psikologis dan (2) hermeneutika gramatikal. Makna folksong yang ditemukan memiliki konsep yang beragam, yaitu (1) konsep komposisi, pertunjukan, dan pewarisan, (2) konsep formula; hubungan larik-larik dan formula persajakan, (3) konsep tema: tema percintaan, rindu, sejarah, petunjuk hidup, atau nasehat, dan tema humor, dan (4) hubungan versi tertulis dan versi lisan. Selain konsep, ditemukan juga fungsi pada makna folksong dalam tradisi Ma'arolo Lani Mala'apa, yaitu sebagai (1) pendidikan, (2) hiburan, (3) sanksi sosial, (4) kritik sosial, (5) peningkat rasa solidaritas, (6) pengubah pekerjaan yang membosankan menjadi pekerjaan yang menyenangkan, dan (7) pengesah pranata-pranata dan lembaga budaya.

Dalam penelitian folksong dalam tradisi Ma'arolo Lani Mala'apa di desa Pelauw Kecamatan Pulau Haruku Maluku Tengah, ada beberapa hal yang selanjutnya dijadikan temuan peneliti yaitu (1) Terdapat pengulangan utuh atau pengulangan keseluruhan folksong dalam tradisi Ma'arolo Lani Mala'apa, (2) masing-masing soa adat memiliki aturan Pengulangan folksong, (3) tidak adanya batas umur dan aturan yang mengatur untuk menjadi seorang Maalani.

\section{DAFTAR PUSTAKA}

Abdurrachman, Paramita R. 1973. Bunga Rampai Sejarah Maluku. Jakarta: Lembaga Penelitian Sejarah Maluku. Apriani, Eny. 2014. Nyanyian Rakyat Suku Tidung di Kota Tarakan Kalimantan Utara (Kajian Struktur Naratif Parry-Lord). Surabaya: Tesis program Pascasarjana Universitas Negeri Surabaya.

Badan Pusat Statistik Kabupaten Maluku Tengah. 2010. Pulau Haruku dalam Angka.

Barth, Fredrik (1988) Kelompok-kelompok Etnik dan Batasannya. Jakarta: Uniniversitas Indonesia (UI-Press).

Bogdan, Robert \& Steven J. Taylor (1992) Pengantar Metode Penelitian Kualitatif (Suatu Pendekatan Fenomenologis Terhadap Ilmu Sosial), Surabaya: Usaha Nasional Indah.

Dananjaja, James. 1997. Folklor Indonesia. Jakarta: Gravity Press

Danandjaja, James.1986. Folklor Indonesia: Ilmu Gosip, Dongeng, dan lain-lain. Jakarta: Penerbit PT Temprint.

Endaswara, Suwardi. 2009. Metodologi Penelitian Folklor. Yokyakarta: Media Pressindo.

Finnegan, Ruth. 1992. Oral traditions and Verbal Arts. London: Chapman and Hall.

Gayatri, Satya. 2006. Formulaik dan Fungsi dalam Pertunjukan Teater Tradisional Tupai Janjang. Padang: Fakultas Sastra Universitas Andalas.

Hutomo, Suripan Sadi. 1987. Cerita Kentrung Sarakwulan di Tuban. Jakarta: Desertasi Program Pascasarjana Universitas Indonesia.

Haviland, William A (1985) Antropologi, Jakarta: Erlangga.

Ihromi, TO (2006) Pokok-Pokok Antropologi Budaya, Jakarta: Yayasan Obor Indonesia.

Koentjaraningrat (2002) Pengantar Ilmu Antropologi, Jakarta: Rineka Cipta

Koentjaraningrat, Metode-Metode Penelitian Masyarakat (Jakarta: Gramedia Pustaka Utama, 1994) 
Latuconsina Y. M, Karakteristik tanah di atas formasi batu gamping koral di wilayah desa Pelauw (2002)

Lexy J. Metode Penelitian Kualitatif (Bandung: Remaja Rosdakarya, 2004)

Lord, B. Albert. 1971. The Singer of Tales. New York: Harvard University Press.

Lord, B. Albert. 1976. The Singer of Tales. New York: Harvard University Press.

Lord, B. Albert. 2002. The Singer of Tales Second Edition. New York: Harvard University Press

Moleong, 2005. Metodologi Penelitian Kualitatif Edisi Revisi. Bandung: Remaja Rosdakarya Offsed.

Phillips, Nigel. 1980. Sijobang Sung Narrative Poetry of West Sumatra. Cambridge: Cambridge University Press.

Rumahuru, Yance Z. 2010. Dinamika Identitas Komunitas Muslim Hatuhaha di Pulau Haruku Maluku Tengah" dalam majalah Masyarakat Indonesia Edisi XXXVI, No. 1.

Ricouer, Paul. 2002. The Interpretation Theory, Filsafat Wacana Membela Makna dalam Anatomi Bahasa. Yogyakarta: IRCiSoD.

Ricouer, Paul. Hermeneutika Ilmu Sosial. Terjemahan oleh Muhammad Syukuri 2006. Yogyakarta: Kreasi Wacana.

Saifuddin, Ahmad Fedyani. 2005. Antropologi Kontemporer: suatu Pengantar Kritis Mengenai Paradigma. Jakarta: Penerbit Prenada Media.

Sudikan, Setya Yuwana. 2001. Metode Penelitian Sastra Lisan. Surabaya: Citra Wacana.

Sudikan, Setya Yuwana. 2001b. Metode Penelitian Sastra Lisan. Surabaya: Citra Wacana.

Sudikan, Setya Yuwana. 2014. Metode Penelitian Sastra Lisan. Lamongan: Pustaka Ilalang Group.

Suratno, Pardi dan Astiyanto, Henniy. 2004. Gusti Ora Sare: 65 Mutiara Nilai
Kearifan Budaya Jawa. Yogyakarta: Penerbit Adiwacana.

Supriyanto, A. dengan judul "Makna Simbolik Mantra dan Perangkat Benda yang digunakan dalam Prosesi Adat Perkawinan suku Sasak di Pringgabaya”. Diambil tanggal 18 Oktober 2015.

Sweeny, Amin. 1999. Kajian Tradisi Lisan dan Pembentukan Wacana Kebudyaan. Makalah Seminar Internasional Tradisi Lisan III. Jakarta tanggal 14-16 Oktober 1999.

Tutuarima, Fricean, dkk. 2009. "Persekutuan Masyarakat Adat Amarima Hatuhaha sebagai Model Pluralitas Sosial" Laporan Penelitian Hibah Strategi Nasional Universitas Pattimura Ambon.

Tuloli, Nani. 1991. Tanggomo Salah Satu Ragam Sastra Lisan Gorontalo. Jakarta: Pustaka Jaya Giri Mukti Pasaka.

Teeuw, A. 1984. Sastra dan Ilmu Sastra Pengantar Teori Sastra. Jakarta: Pustaka Jaya Giri Mukti Pasaka.

Wahab, Abdul. 1998. Isu Linguistik: Pengajaran Bahasa dan Sastra. Surabaya: Airlangga University Press.

Winaryo. 2014. Seni Maca'an Lare Using Kabupaten Banyuwangi: Perspektif Teori Parry-Lord. Surabaya: Tesis Pascasarjana universitas Negeri Surabaya. 